\title{
ACUTE TOXICITY STUDY OF TOMATO POMACE EXTRACT IN RODENT
}

\author{
${ }^{1}$ Wathita Phachonpai, ${ }^{2,3}$ Supaporn Muchimapura, ${ }^{2,3}$ Terdthai Tong-Un, \\ ${ }^{2,3}$ Jintanaporn Wattanathorn, ${ }^{2,3}$ Wipawee Thukhammee, ${ }^{2,3}$ Chonlathip Thipkaew, \\ ${ }^{4}$ Bungorn Sripanidkulchai and ${ }^{2,3}$ Panakaporn Wannanon
}

\author{
${ }^{1}$ Division of Physiology, School of Medical Science, University of Phayao, Phayao, 56000, Thailand \\ ${ }^{2}$ Department of Physiology, Faculty of Medicine, Khon Kaen University, Khon Kaen, 40002, Thailand \\ ${ }^{3}$ Integrative Complementary Alternative Medicine Research Center, \\ Khon Kaen University, Khon Kaen, 40002, Thailand \\ ${ }^{4}$ Center for Research and Development of Herbal Health Product, \\ Faculty of Pharmaceutical Science, Khon Kaen University, 40002, Thailand
}

Received 2012-04-23, Revised 2012-05-02; Accepted 2013-05-14

\begin{abstract}
Tomato and tomato products are considered to be healthy food for the human diet. Although tomatoes have been widely studied for their phenolic content, less emphasize has been laid on toxicological effect of this plant. Thus, the purpose of the present study is to determine the acute toxicity effect of Lycopersicon esculentum, or commonly known as tomato, was administered orally in the form of dried tomato pomace extract in vivo. Adult male rats were orally administrated single dose of 1000 and $5000 \mathrm{mg} \mathrm{kg}^{-1} \mathrm{dried}$ tomato pomace extract. There were 10 rats in each group. All animals were sacrificed after 2 weeks of treatment. Seven parameters were tested: cage side observation, body weight gain measurement, food and water consumption, absolute organ weight, hematology, biochemical analysis and histopathology, to look for evidence of acute toxicity. No mortality was observed when varying doses of the extracts were administered per day for a period of 2 weeks. There were no significant differences in body weight, behavior, food consumption, absolute organ weights between controls and treated animals. Hematological analysis showed no differences in most parameters examined. In the biochemistry parameter measurement, no significant change occurred. Pathologically, neither gross abnormalities nor histopathological changes were observed. These finding suggest that none of the organs appeared to be target and the data could provide satisfactory preclinical evidence of safety to launch clinical trial on standardized formulation of tomato pomace extracts to be the dietary supplement.
\end{abstract}

Keywords: Lycopersicon Esculentum, Acute Toxicity, Tomato Pomace, Dietary Supplement

\section{INTRODUCTION}

Several studies have suggested a strong link between dietary phytochemical intakes and a reduced risk for chronic diseases, including cancer and coronary artery disease. Dietary antioxidants from fruits and vegetables, which are rich sources of antioxidants and many studies have shown that an important food sector promoting health benefits and reduce the risk of chronic disease via functional ingredients in these products (Verschuren, 2002; Phachonpai et al., 2012).

Tomato or Lycopersicon Esculentum (L. esculentum) consumption worldwide has greatly increased over the past 2 decades. It had been reported that consumption of tomato or tomato products has been associated with decreased risk of some cancers and prevented illness, promoting growth (Shi and Maguer, 2000) and proper immune system functioning (Sandhu et al., 2000). In Khon Kaen, 40002, Thailand Tel: 66-43-348394 Fax: 66-43-348394 
addition, tomato also contains valuable phytochemicals and antioxidants including carotenoids such as lycopene and beta-carotene (Canene-Adams et al., 2005).

Recently, previous studied reported that the waste product of tomato or tomato pomace obtained from food industry processing contained skin, pulp and crushed seeds of tomato were still contains lycopene and betacarotene (Sabio et al., 2003). It had been reported that dried tomato pomace exhibited cognitive enhancing effect in normal and cognitive impairment conditions (Thukhammee et al., 2012). Therefore, the development tomato pomace extract as functional food or dietary supplementation is very much interesting. However, less emphasize has been laid on toxicological effect of this extract. Information about toxicity of dried tomato pomace extract is very important as a baseline before exploring further to develop this extract as a new herbal dietary supplement. Therefore, the purpose of the present study is to determine the acute toxicity effect of dried tomato pomace extract in healthy male rats.

\section{MATERIALS AND METHODS}

Preparation of dried tomato pomace powder: Tomato pomace is consisting of tomato skins, pulp and crushed seeds that remain after the processing of tomatoes for juice. Wet tomato pomace was dried with oven at $50^{\circ} \mathrm{C}$ for $2 \mathrm{~h}$. The \%yield of tomato pomace is 12.75 . The dried tomato pomace was grinded as powder and determined both lycopene level and total phenolic compound and used as markers for quality control. It was found that the dried tomato pomace contained lycopene $160.94 \mathrm{mg} 100$ $\mathrm{g}^{-1}$ sample while contained total phenolic compound $413.07 \pm 34.45 \mathrm{mg}$ of gallic acid equivalent $/ \mathrm{mg}$. The dried tomato pomace was kept in airtight container at room temperature until use.

\subsection{Animals}

Adult male Wistar rats (180-200 g, 8 weeks old) were obtained from Animal Unit, Faculty of Medicine, Khon Kaen University and were housed in group of 5 per cage in standard metal cages at $22 \pm 2^{\circ} \mathrm{C}$ on $12: 12 \mathrm{~h}$ lightdark cycle. All animals were given access to food and water ad libitum. Experiments were performed to minimize animal suffering in accordance with the internationally accepted principles for laboratory use and care of European Community (EEC directive of 1986; 86/609/EEC) and approved by the Ethical Committee of the Khon Kaen University.

\subsection{Dosage of Extract on Animals}

Single dose toxicity studies were carried out by adapting OECD guideline nos. 423 (OECD, 2003). In order to study any possible toxic effect or changes in normal behavior, 2 groups of rat (all males) were used in this experiment. The acute toxicity of the extract was studied by preparing two different concentrations of the standardized extract (1000 and $5000 \mathrm{mg} \mathrm{kg}^{-1}$ ) and administrated orally using a feeding needle to two groups of animals. The third group was taken as a control and given as vehicle (distilled water). The maximum volume of distilled water administered was not greater than $2 \mathrm{~mL} 100^{-1} \mathrm{~g} \mathrm{BW}$. Animals were fasted prior to conducting the experiment (only food but not water was withheld overnight). Following the $24 \mathrm{~h}$ of fasting, the animals were weighed and the test substance was administered. After the substance has been administered, food may be withheld for a further 3-4 h. The acute toxic effects of the extract were assessed on the basis of mortality, which was expressed as LD50. Lethal Dose (LD 50) was calculated using the following equation (Turner, 1965):

LD50 $=$ the apparent least dose lethal to all in a group $-\Sigma$ (axb) $/ \mathrm{N}$

\subsection{Cage Side Observation and Body Weight Measurement}

All animals were observed individually after substances administration and special attention was given during the first $4 \mathrm{~h}$ and every $12 \mathrm{~h}$ daily thereafter, for a total of 2 weeks. All observations were systematically recorded, with individual records being maintained for each animal. Cage side observation included evaluation of fur and skin, eyes, respiratory effects, autonomic effects such as salivation, diarrhea, urination and the central nerve effects including tremors and convulsions, changes in the level of activity, gait and posture, reactivity to handling or sensory stimuli and altered strength (Kumarnsit et al., 2006; Demma et al., 2006; Mukinda and Syce, 2007; Obici et al., 2008). Individual body weight was measured and recorded prior to the oral administration of extracts for 2 weeks. Weight changes were also calculated and recorded.

\subsection{Food Consumption}

Amount of food consumed was measured daily from the quantity of food supplied and the amount remaining after $24 \mathrm{~h}$ for 2 weeks of the study period (Kumarnsit et al., 2006; Demma et al., 2006; Obici et al., 2008). 


\subsection{Hematology}

At the end of the acute toxicity study (2 weeks), all animals were sacrificed and bled via inferior vena cava puncture. The samples were collected in plastic test tubes containing EDTA anti-clotting. Hematological examinations included the following parameters: White Blood cell Count (WBC), Red Blood cell Count (RBC), Hemoglobin concentration $(\mathrm{Hb})$, Hematocrit $(\mathrm{Ht})$, Platelet count (PLT), Mean Corpuscular Volume (MCV), Mean Corpuscular Hemoglobin $(\mathrm{MCH})$ and Mean Corpuscular Hemoglobin Concentration (MCHC) (Demma et al., 2006; Obici et al., 2008; Tan et al., 2008).

\subsection{Biochemical Analysis}

Serum biochemistry was performed to examine Aspartate aminotransferase (AST), Alanine Aminotransferase (ALT), Alkaline Phosphatase (ALP), Creatinine (CRN), Triglycerides (TG), Cholesterol (Cho), Total Bilirubin (T-Bil), Blood Urea Nitrogen (BUN) and Blood Sugar (BS) (Demma et al., 2006; Obici et al., 2008; Tan et al., 2008).

Analyses for hematology and serum biochemistry were conducted at the laboratory of Srinagarind Hospital, Faculty of Medicine, Khon Kaen University, Thailand.

\subsection{Absolute and Relative Organ Weight}

At the end of the acute toxicity study ( 2 weeks), all organs were collected using standardized surgical procedures. The abdominal cavity of each animal was dissected and organs namely the heart, liver, lungs, spleen, kidneys, adrenals, thymus, salivary gland and brain were quickly removed, cleaned with saline, weighed and preserved in $10 \%$ formalin for histopathology analyses (Demma et al., 2006; Obici et al., 2008; Tan et al., 2008).

\subsection{Histopathological Observation}

The four organs of all rats (heart, lung, liver and kidney) were examined macroscopically. The morphology of the internal organs was visually observed for signs of toxicity. These organs have undergone Hematoxylin and Eosin ( $\mathrm{H}$ and $\mathrm{E})$ staining. Abnormalities of the slides were graded as mild, moderate and severe (Jain et al., 2008; Tan et al., 2008).

\subsection{Statistical Analysis}

Nonparametric one way statistical analysis of variance, Kruskal-Wallis test and posthoc test (Mann-
Whitney test) were used in order to see any significant changes between Tomato pomace extract groups and vehicle treated group. Differences between groups were considered significant at $p<0.05$. All data points show the mean of Standard Error of Means (SEM).

\section{RESULTS}

In this study, the oral administrations of the dried tomato pomace at all dosages were given for 2 weeks did not produce any visible sign of acute toxicity or instant death in rats tested during the period of observation.

\subsection{Food Consumption and Body Weight Measurement}

The amount of food consumed was measured daily from the quantity of food supplied and the amount remaining after $24 \mathrm{~h}$. Values for consumption are based on total intake and average relative body weight of the preceding time interval. These data showed no statistically significant difference between any groups (Table 1).

The mean of rats' body weight was measured daily for 14 consecutive days. Again, there is no statistically significant difference between any groups in this parameter.

\subsection{Cage side Observation}

All the three doses of Tomato pomace extract did not produce significant changes in behavior, skin effect, breathing, defecation, postural abnormalities, yellowing or loss of hair.

\subsection{Organ weights}

As shown in Table 2, the mean of each organ weights did not differ between the extract treated and the control groups.

\subsection{Hematological and the Serum Biochemical Parameters}

The serum biochemical and blood hematology results for the rats are presented in Table 3 and 4 respectively. No statistically significant difference was shown among treated groups.

\subsection{Histopathology}

Our histopathology results were shown in Fig. 1. There are no significant morphological changes detected in kidney, heart, lung and liver in all rat samples from all groups of study. 


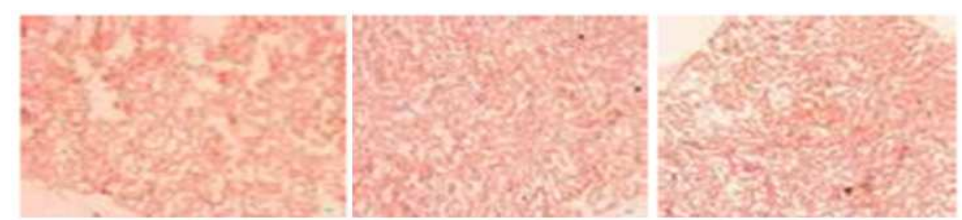

(A)

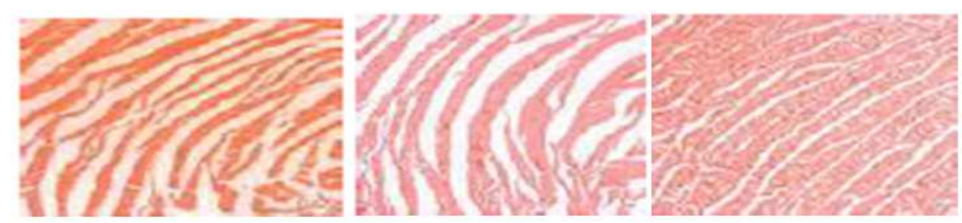

(B)

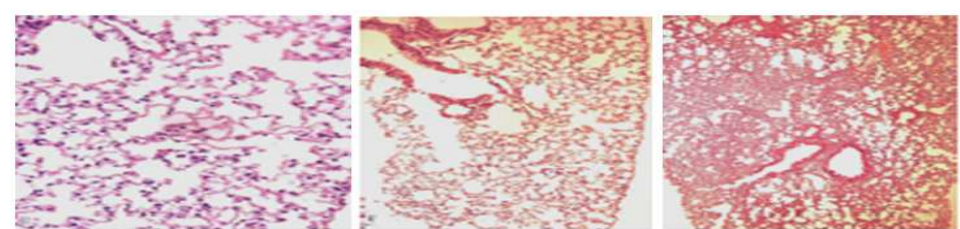

(C)
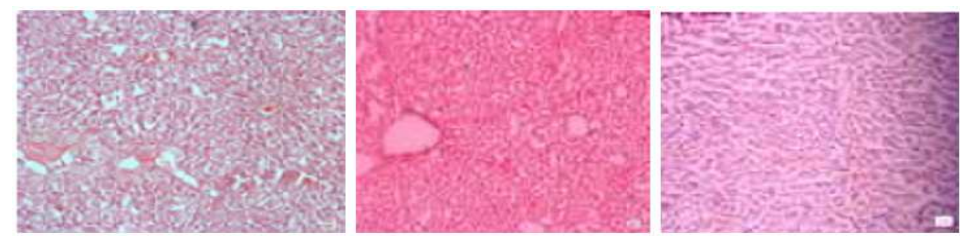

(D)

Fig. 1. (A) Kidney sections were stained with hematoxylin and eosin ( $\mathrm{H}$ and $\mathrm{E}$ stained $10 \mathrm{x})$ (B) Heart sections were stained with hematoxylin and eosin (H and E stained 20x) (C) Lung sections were stained with hematoxylin and eosin ( $\mathrm{H}$ and $\mathrm{E}$ stained 40x) (D) Liver sections were stained with hematoxylin and eosin (H and E stained 10x) Vehicle, TP 1000 and TP 5000 treated groups, respectively

Table 1. Effect of the dried tomato pomace on body weight and food consumption in rats

\begin{tabular}{lllll}
\hline Group & $\begin{array}{l}\text { Food consumption } \\
(\mathrm{g} / \text { day })\end{array}$ & Initial weight & $\begin{array}{l}\text { Body weight }(\mathrm{g}) \\
\text { Final weight }\end{array}$ & Weight gain $(\%)$ \\
\hline Vehicle & $18.43 \pm 0.52$ & $350.01 \pm 1.11$ & $379.13 \pm 1.59$ & 6.10 Tomato \\
pomace $1000 \mathrm{mg} \mathrm{kg}^{-1}$ & $19.40 \pm 0.57$ & $349.86 \pm 1.07$ & $375.78 \pm 1.22$ & 6.16 Tomato \\
pomace $5000 \mathrm{mg} \mathrm{kg}^{-1}$ & $19.33 \pm 0.34$ & $348.82 \pm 1.03$ & $375.00 \pm 1.83$ & 6.23 \\
\hline
\end{tabular}

Table 2. Effect of the dried tomato pomace on organ weights in rats

\begin{tabular}{|c|c|c|c|}
\hline Group & Heart $\left(\mathrm{g} \mathrm{kg}^{-1} \mathrm{BW}\right)$ & Lung ( $\left.\mathrm{g} \mathrm{kg}^{-1} \mathrm{BW}\right)$ & Liver $\left(\mathrm{g} \mathrm{kg}^{-1} \mathrm{BW}\right)$ \\
\hline Vehicle & $3.10 \pm 0.02$ & $6.64 \pm 0.18$ & $29.70 \pm 0.14$ \\
\hline Tomato pomace $1000 \mathrm{mg} \mathrm{kg}^{-1}$ & $3.18 \pm 0.04$ & $6.58 \pm 0.18$ & $29.12 \pm 0.15$ \\
\hline \multirow[t]{2}{*}{ Tomato pomace $5000 \mathrm{mg} \mathrm{kg}^{-1}$} & $3.25 \pm 0.02$ & $6.39 \pm 0.14$ & $28.15 \pm 0.18$ \\
\hline & Brain $\left(\mathrm{g} \mathrm{kg}^{-1} \mathrm{BW}\right)$ & Kidneys $\left(\mathrm{g} \mathrm{kg}^{-1} \mathrm{BW}\right)$ & Thymus $\left(\mathrm{g} \mathrm{kg}^{-1} \mathrm{BW}\right)$ \\
\hline Vehicle & $15.06 \pm 0.02$ & $8.14 \pm 0.02$ & $2.35 \pm 0.02$ \\
\hline Tomato pomace $1000 \mathrm{mg} \mathrm{kg}^{-1}$ & $15.13 \pm 0.09$ & $8.15 \pm 0.03$ & $2.31 \pm 0.02$ \\
\hline \multirow{2}{*}{ Tomato pomace $5000 \mathrm{mg} \mathrm{kg}^{-1}$} & $15.14 \pm 0.03$ & $8.16 \pm 0.03$ & $2.39 \pm 0.02$ \\
\hline & $\begin{array}{l}\text { Salivary gland } \\
\left(\mathrm{g} \mathrm{kg}^{-1} \mathrm{BW}\right)\end{array}$ & $\begin{array}{l}\text { Adrenal gland } \\
\left(\mathrm{g} \mathrm{kg}^{-1} \mathrm{BW}\right)\end{array}$ & $\begin{array}{l}\text { Spleen }\left(\mathrm{g} \mathrm{kg}^{-1} \mathrm{BW}\right) \\
\left(\mathrm{g} \mathrm{kg}^{-1} \mathrm{BW}\right)\end{array}$ \\
\hline Vehicle & $1.40 \pm 0.01$ & $0.72 \pm 0.01$ & $3.33 \pm 0.02$ \\
\hline Tomato pomace $1000 \mathrm{mg} \mathrm{kg}^{-1}$ & $1.39 \pm 0.01$ & $0.71 \pm 0.02$ & $3.32 \pm 0.05$ \\
\hline Tomato pomace $5000 \mathrm{mg} \mathrm{kg}^{-1}$ & $1.40 \pm 0.01$ & $0.70 \pm 0.02$ & $3.24 \pm 0.02$ \\
\hline
\end{tabular}


Table 3. Effect of the dried tomato pomace on serum biochemical parameters of rats

\begin{tabular}{lllll}
\hline Group & $\mathrm{BS}(\mathrm{mg} / \mathrm{dl})$ & Chol $(\mathrm{mg} / \mathrm{dl})$ & $\mathrm{TG}(\mathrm{mg} / \mathrm{dl})$ & $\mathrm{BUN}(\mathrm{mg} / \mathrm{dl})$ \\
\hline Vehicle & $97.25 \pm 1.99$ & $61.83 \pm 0.57$ & $65.25 \pm 1.19$ & $10.75 \pm 0.39$ \\
Tomato pomace $1000 \mathrm{mg} \mathrm{kg}^{-1}$ & $97.67 \pm 1.70$ & $61.33 \pm 0.79$ & $64.44 \pm 1.59$ & $11.51 \pm 0.43$ \\
Tomato pomace $5000 \mathrm{mg} \mathrm{kg}^{-1}$ & $96.83 \pm 1.07$ & $60.17 \pm 0.61$ & $62.42 \pm 0.89$ & $11.45 \pm 0.52$ \\
& $\mathrm{CRN}(\mathrm{mg} / \mathrm{dl})$ & $\mathrm{ALT}(\mathrm{U} / \mathrm{L})$ & $\mathrm{AST}(\mathrm{U} / \mathrm{L})$ & ALP $(\mathrm{U} / \mathrm{L})$ \\
Vehicle & $0.38 \pm 0.00$ & $32.89 \pm 0.61$ & $69.58 \pm 1.74$ & $37.00 \pm 0.45$ \\
Tomato pomace $1000 \mathrm{mg} \mathrm{kg}^{-1}$ & $0.37 \pm 0.01$ & $33.11 \pm 0.57$ & $69.44 \pm 1.70$ & $37.67 \pm 0.73$ \\
Tomato pomace $5000 \mathrm{mg} \mathrm{kg}^{-1}$ & $0.37 \pm 0.01$ & $33.17 \pm 0.44$ & $69.50 \pm 1.71$ & $38.42 \pm 0.61$ \\
& $\mathrm{~T}-\mathrm{Bil}(\mathrm{mg} / \mathrm{dl})$ & & & \\
\hline
\end{tabular}

\begin{tabular}{lr}
\hline Vehicle & $0.10 \pm 0.00$ \\
Tomato pomace $1000 \mathrm{mg} \mathrm{kg}^{-1}$ & $0.10 \pm 0.00$ \\
Tomato pomace $5000 \mathrm{mg} \mathrm{kg}^{-1}$ & $0.10 \pm 0.00$
\end{tabular}

Table 4. Effect of the dried tomato pomace on blood hematology parameters of rats

\begin{tabular}{lllll}
\hline Group & WBC $\left(\times 10^{3}\right)$ & $\mathrm{RBC}\left(\times 10^{6}\right)$ & $\mathrm{Hb}(\mathrm{g} / \mathrm{dl})$ & $\mathrm{Hct}(\%)$ \\
\hline Vehicle & $3.61 \pm 0.15$ & $8.58 \pm 0.08$ & $12.68 \pm 0.21$ & $40.96 \pm 0.45$ \\
Tomato pomace $1000 \mathrm{mg} \mathrm{kg}^{-1}$ & $3.62 \pm 0.10$ & $8.94 \pm 0.15$ & $12.86 \pm 0.19$ & $40.95 \pm 0.48$ \\
Tomato pomace $5000 \mathrm{mg} \mathrm{kg}^{-1}$ & $3.72 \pm 0.08$ & $9.06 \pm 0.12$ & $13.07 \pm 0.16$ & $41.66 \pm 0.19$ \\
& $\mathrm{MCV}(\mathrm{fL})$ & $\mathrm{MCH}(\mathrm{pg})$ & $\mathrm{MCHC}(\mathrm{g} / \mathrm{dl})$ & $\mathrm{PLT}\left(\times 10^{3}\right)$ \\
Vehicle & $47.46 \pm 0.46$ & $15.23 \pm 0.12$ & $32.17 \pm 0.16$ & $46.00 \pm 1.31$ \\
Tomato pomace $1000 \mathrm{mg} \mathrm{kg}^{-1}$ & $48.42 \pm 0.50$ & $15.24 \pm 0.15$ & $32.06 \pm 0.19$ & $46.15 \pm 1.48$ \\
Tomato pomace $5000 \mathrm{mg} \mathrm{kg}^{-1}$ & $49.78 \pm 0.31$ & $15.85 \pm 0.14$ & $31.36 \pm 0.05$ & $47.02 \pm 1.41$ \\
\hline
\end{tabular}

\section{DISCUSSION}

Recently, from the point of view of "selfmedication" or "preventive medicine," several herbal dietary supplements are used in the prevention of lifestyle related diseases. Our results for the preliminary toxicological screening reveal that the oral administration of dried tomato pomace powder is non toxic substance.

Usually acute (single dose) toxicity study is carried out on laboratory animals by using high dose (sufficient to produce death or morbidity) of the substance in question and/or based on previous report on its toxicity or toxicity of structurally related compounds. Unfortunately, there was no previous report on toxicity of dried tomato pomace extract consumption. Therefore, only two dose levels, the limit dose (usually a dose of $5000 \mathrm{mg} \mathrm{kg}^{-1}$ is considered limit dose in single dose toxicity study) and another low dose (1000 mg kg-1), were selected in single dose toxicity studies of tomato pomace extract powder. In this 2 weeks period of acute toxicity evaluation, rats given dried this extract at dose of 1000 and $5000 \mathrm{mg} \mathrm{kg}^{-1} \mathrm{BW}$, showed no mortality and all rats did not produce any symptom of toxicity. This finding is in accordance with the previous report of dried tomato pomace effect in rats (Thukhammee et al., 2012). However, the dose of the extract, the species of animals and the duration of treatment of the plant extract were different. Moreover, our result on cage side functional observations such as respiratory, autonomic and nervous system effects in all doses of the extract treated group animals did not produce the toxic effects on these parameters as mention already.

Regardless of the dose used, the tomato pomace extract did not appear to affect the body weight of the rats and caused no significant changes in their food consumption. Utilization of food exhibited normal metabolism in the animals (Mukinda and Syce, 2007) and this suggests that the single oral dose of the extract did not retard the growth of rats. However, the effect of tomato pomace extract on the alteration of body weight gain seems to be in contradiction to the results from (Friedman et al., 2000), who reported that both red and green tomatoes contain glycoalkaloids, is a natural toxin substance could reduce body weight gain in hamsters (Friedman et al., 1994; 2000). One possible explanation for the difference between both phenomenons as mention above that may result from the differences of animal species, doses of the extract and the duration of treatment. However, this study did not investigate about the possible active ingredients and the precise underlying mechanisms of tomato pomace extract on body weight gain; this is planned in future studies.

Our finding indicates that all animals from tomato pomace extract groups showed no significant changes in the absolute organ weights of the heart, liver, lungs, spleen, kidneys, adrenals, thymus, salivary gland and 
brain of the rats treated with this extract compared to vehicle control treated group. Similarly, no damage or structural modification was observed during the macroscopic evaluation of important organs such as the liver, kidney, brain and heart of the treated animals when compared with the control group.

The various biochemical and hematological parameters investigated in this study are useful indices of evaluating the toxicity of the extract in animals. Measurement of hematological parameters can be used to investigate the extent of deleterious effect of foreign compounds including plant extracts on the blood constituents of an animal. It can also be used to explain blood relating functions of chemical compounds and plant extracts (Oyedemi et al., 2011). The biochemical parameters were used as indices for assessing organ dysfunction or damage as could arise in toxicity especially the liver plays an important role in many metabolic processes; any disturbance in the liver would affect the normal level of measurable biochemical parameters in this organ. AST, ALT and ALP are marker enzymes present in high concentrations in the liver, when liver cells are inflamed or damaged, these enzymes leak into the blood stream leading to a rise in the plasma level of these enzymes (Nkosi et al., 2005). However, the results of both hematological and biochemical parameters of the present study did not show any worrisome results since all the changes were within the normal expected range for the rat species used in this study.

Taken all data together, the results in this study showed that the acute administration of the dried tomato pomace at all given doses (up to $5000 \mathrm{mg} \mathrm{kg}^{-1}$ ) did not produce any sign of acute toxicity in rats tested during the period of observation. This, however, suggest that the extract has no acute toxicity when administered orally and the lethal dose if any is above $5000 \mathrm{mg} \mathrm{kg}^{-1}$. Clarke and Clarke (1975) reported that substances with LD50 of $1000 \mathrm{mg} \mathrm{kg}^{-1} \mathrm{BW}$ given orally are considered safe or of low toxicity. Similarly, the chemical labeling and classification of acute systemic toxicity based on oral LD50 values recommended by the Organization for Economic Cooperation and Development (OECD, Paris, France) (Walum, 1998) are as follow: very toxic, $<5 \mathrm{mg}$ $\mathrm{kg}^{-1}$; toxic, $>5<50 \mathrm{mg} \mathrm{kg}^{-1}$; harmful, $>50<500 \mathrm{mg} \mathrm{kg}^{-1}$ and no label, $>500<2000 \mathrm{mg} \mathrm{kg}^{-1}$. Therefore, the expected high LD50 (>5000 mg kg-1 $\mathrm{BW})$ of the dried extract tomato pomace, is an indication that the extract could be considered relatively safe especially when administered orally where absorption may not be complete due to inherent factors limiting absorption in the gastro intestinal tract. Although, obtaining a lethal dose in animals may not predict the human lethal dose of a drug or acute poisoning overdose (Chapman et al., 2010). However, these findings could provide satisfactory preclinical evidence of safety to launch clinical trial on standardized formulation of tomato pomace extract to be the herbal dietary supplement.

\section{CONCLUSION}

In a nutshell, the data of the present study do suggest that oral administration of dried tomato pomace is not toxic. Obviously, this study points to the need for additional studies to better define the roles of tomato consumption that may be responsible for the beneficial effects. No less challenging, but potentially beneficial for human health, would be an assessment whether the cited effects in rats parallel those in humans.

\section{ACKNOWLEDGMENT}

This study was supported by the National Research Council of Thailand and Integrative Complimentary Alternative Medicine Research and Development Group, Khon Kaen University, Thailand. The authors have no conflict of interest to report.

\section{REFERENCES}

Canene-Adams, K., J.K. Campbell, S. Zaripheh, E.H. Jeffery and J.W. Jr. Erdman, 2005. The tomato as a functional food. J. Nutr., 135: 1226-1230. PMID: 15867308

Chapman, K., S. Cretona, H. Kupferschmidtb, G.R. Bond and M.F. Wilksd et al., 2010. The value of acute toxicity studies to support the clinical management of overdose and poisoning: A cross-discipline consensus. Regulatory Toxicol. Pharmacol., 58: 354359. DOI: 10.1016/j.yrtph.2010.07.003

Clarke, E.G.C. and M.L. Clarke, 1975. Veterinary Toxicology. 1st Edn., Bailliere Tindall, London, ISBN-10: 0702005568, pp: 438.

Demma, J., T. GebreMariam, K. Asres, W. Evgetie and E. Engindawork, 2006. Toxicological study on Glinus lotoides: A traditionally used taenicidal herb in Ethiopia. J. Ethnopharmacol., 111: 451-457. DOI: 10.1016/j.jep.2006.12.017

Friedman, M., C.E. Levin and G.M. McDonald, 1994. $\alpha-$ Tomatine determination in tomatoes by HPLC using pulsed amperometric detection. J. Agric. Food Chem., 42: 1959-1964. DOI: 10.1021/jf00045a024 
Friedman, M., T.E. Fitch, C.E. Levin and W.H. Yokoyama, 2000. Feeding tomatoes to hamsters reduces their plasma low-density lipoprotein cholesterol and triglycerides. J. Food Sci., 65: 897900. DOI: 10.1111/j.1365-2621.2000.tb13608.x

Jain, A., M. Soni, L. Deb, A. Jain and S.P. Rout et al., 2008. Antioxidant and hepatoprotective activity of ethanolic and aqueous extracts of Momordica dioica Roxb. leaves. J. Ethnopharmacol., 115: 61-66. DOI: 10.1016/j.jep.2007.09.009

Kumarnsit, E., N. Keawpradub and W. Nuankaew, 2006. Acute and long-term effects of alkaloid extract of Mitragyna speciosa on food and water intake and body weight in rats. Fitoterapia, 77: 339-345. DOI: 10.1016/j.fitote.2006.04.006

Mukinda, J.T. and J.A. Syce, 2007. Acute and chronic toxicity of the aqueous extract of Artemisia afra in Rodent. J. Ethnopharmacol., 111: 138-144. DOI: 10.1016/j.jep.2007.02.011

Nkosi, C.Z., A.R. Opoku and S.E. Terblanche, 2005. Effect of pumpkin seed (Cucurbita pepo) protein isolate on the activity levels of certain plasma enzymes in CCl4-induced liver injury in low-protein fed rats. Phytother. Res., 19: 341-345. DOI: $10.1002 /$ ptr. 1685

Obici, S., F.J. Otobone, V.R.D.S. Sela, K. Ishida and J.C.D. Silva et al., 2008. Preliminary toxicity study of dichloromethane extract of Kielmeyera coriacea stems in mice and rats. J. Ethnopharmacol., 115: 131-139. DOI: 10.1016/j.jep.2007.09.013

OECD, 2003. OECD Guidelines for Testing of Chemicals. OECD-Organisation for Economic Cooperation and Development.

Oyedemi, S.O., E.A. Adewusi, O.A. Aiyegoro and D.A. Akinpelu, 2011. Antidiabetic and haematological effect of aqueous extract of stem bark of Afzelia africana (Smith) on streptozotocin-induced diabetic Wistar rats. Asian Pacific J. Tropical Biomed., 1: 353-358. DOI: 10.1016/S2221-1691(11)60079-8
Phachonpai, W., S. Maharun, T. Tong-Un, S. Muchimapura and J. Wattanathorn, 2012. The functional effect of kaempferia parviflora on ischemic stroke in rats. Am. J. Agric. Biol. Sci., 7: 173-179. DOI: 10.3844/ajabssp.2012.173.179

Sabio, E., M. Lozano, E.V. Montero, M.L. Mendes and A.P. Pereira et al., 2003. Lycopene and $\beta$-carotene extraction from tomato processing waste using supercritical $\mathrm{CO}_{2}$. Ind. Eng. Chem. Res., 42: 66416646. DOI: 10.1021/ie0301233

Sandhu, J.S., S.F. Krasnyanski, L.L. Domier, S.S. Korban and M.D. Osadjan et al., 2000. Oral immunization of mice with transgenic tomato fruit expressing respiratory syncytial virus-F protein induces a systemic immune response. Trans. Res., 9: 127-135. DOI: 10.1023/A:1008979525909

Shi, J. and M.L. Maguer, 2000. Lycopene in tomatoes: Chemical and physical properties affected by food processing. Crit. Rev. Food Sci. Nutr., 40: 1-42. DOI: 10.1080/10408690091189275

Tan, P.V., C. Mezui, G. EnowOrock, N. Njikam and T. Dimo et al., 2008. Teratogenic effects, acute and sub chronic toxicity of the leaf aqueous extract of Ocimum suave Wild (Lamiaceae) in rats. J. Ethnopharmacol., 115: 232-237. DOI: 10.1016/j.jep.2007.09.022

Thukhammee, W., J. Wattanathorn, S. Muchimapura, J. Uriyapongson and T. Tong-Un et al., 2012. The cognitive enhancing effect of tomato pomace. Am. J. Applied Sci., 9: 946-951. DOI: 10.3844/ajassp.2012.946.951

Turner, R.A., 1965. Screening Methods in Pharmacology. 1st Edn., Academic Press, California, pp: 332.

Verschuren, P.M., 2002. Functional foods: Scientific and global perspectives. Br. J. Nutr., 88: S125-S130. DOI: $10.1079 / \mathrm{BJN} 2002675$

Walum, E., 1998. Acute oral toxicity. Environ. Health Perspect., 106: 497-503. DOI: 10.2307/3433801 